\title{
Eficácia de herbicidas no controle de plantas daninhas e seletividade na cultura do amendoim Runner IAC $886^{1}$
}

\author{
Effectiveness of herbicides in weed control and selectivity in culture Runner IAC \\ 886 peanut
}

\section{Rafael Alves Luvezuti²; Allan Lopes Bacha ${ }^{3}$; Pedro Luís da Costa Aguiar Alves ${ }^{4}$; Maria do Carmo Morelli Damasceno Pavani ${ }^{4}$; Mariluce Pascoina Nepomuceno ${ }^{5}$}

\begin{abstract}
Resumo - Objetivou-se verificar a eficácia e a seletividade de herbicidas aplicados isoladamente ou em mistura, no controle de plantas daninhas infestantes da cultura do amendoim Runner IAC 886. Para tanto, instalou-se um experimento a campo, em delineamento de blocos casualizados, com quatro repetições. Os tratamentos aplicados em pré-emergência foram: 1-imazapic, 3imazapic + pendimetalina e 5-imazapic + trifluralina; os aplicados em pós-emergência foram: 2imazapic, 4-imazapic + pendimetalina e 10-imazapic + (bentazon + paraquat); e os tratamentos com aplicação em pré seguido de pós, foram: 6-trifluralina e imazapic, 7-trifluralina e bentazon, 8trifluralina e 2,4-D, 9-imazapic e bentazon + paraquat; além das testemunhas com e sem capina (tratamentos 11 e 12, respectivamente). Foram avaliados a eficácia dos herbicidas e os sintomas de intoxicação nas plantas de amendoim por avaliações visuais aos 7, 14, 21, 28, 45 e 90 dias após a aplicação, e após a colheita, a produtividade de vagens. Os tratamentos $2,3,4,5,6,7$ e 8 não tiveram redução significativa na produtividade. $\mathrm{O}$ tratamento 10 foi o menos eficiente no controle das plantas daninhas e apresentou produtividade $47,3 \%$ menor que o tratamento 3 e 51,2\% menor que a testemunha capinada. Conclui-se que para uma comunidade infestante composta principalmente por Cenchrus echinatus, Acanthospermum hispidum, Amaranthus deflexus, Parthenium hysterophorus, Alternanthera tenella e Eleusine indica, o melhor controle das plantas daninhas foi obtido por imazapic em pós-emergência. A aplicação de imazapic + (bentazon + paraquat) em pós-emergência, não foi efetiva no controle das plantas infestantes, resultando em perdas de produtividade.
\end{abstract}

Palavras-chaves: Arachis hypogaea L., fitotoxicidade, produtividade

Abstract - It was aimed to verify the efficacy and selectivity of herbicides applied alone or in tank mixture for the weed control in peanut crop cv Runner IAC 886. Therefore, it was settled a field experiment, in a randomized block design with four replications. The treatments applied in pre-emergence were: 1-imazapic, 3-imazapic + pendimethalin, and 5-imazapic + trifluralin; the treatments applied in post-emergence were: 2-imazapic, 4-imazapic + pendimethalin, and 10-

\footnotetext{
${ }^{1}$ Recebido para publicação em 26/11/2014 e aceito em 24/07/2015.

${ }^{2}$ Engenheiro Agrônomo - FCAV/UNESP, Via de Acesso Prof. Paulo Donato Castellane s/n 14884-900 - Jaboticabal, SP, Brasil.

${ }^{3}$ Mestrando em Produção Vegetal - FCAV/UNESP. Jaboticabal, SP. E-mail: allan_lb@ hotmail.com (*autor para correspondência).

${ }^{4}$ Professores do Departamento de Biologia Aplicada à Agropecuária - FCAV/UNESP. Jaboticabal, SP.

${ }^{5}$ Pós-doutoranda em Produção Vegetal - FCAV/UNESP. Jaboticabal, SP.
} 
imazapic + (bentazon + paraquat); and treatments with application in PRE followed by POST were: 6-trifluralin and imazapic, 7-trifluralin and bentazon, 8-trifluralin and 2,4-D, 9-imazapic and bentazon + paraquat; besides the checks with and without weeding (treatments 11 and 12, respectively). It were evaluated the efficacy of herbicides and symptoms of intoxication in peanut plants by visual evaluations at 7, 14, 21, 28, 45, and 90 days after application, and, after the harvest, the pods yields. Treatments $2,3,4,5,6,7$, and 8 had no significant reduction in peanut productivity. Treatment 10 was the least effective in controlling weeds and presented yields $47.3 \%$ lower than treatment 3 and 51.2\% lower than the weeded control. It was concluded that for a weed community composed mainly of Cenchrus echinatus, Acanthospermum hispidum, Amaranthus deflexus, Parthenium hysterophorus, Alternanthera tenella, and Eleusine indica, the best weed control was obtained by imazapic in post-emergence. The application of imazapic + (bentazon + paraquat) in post-emergence was not effective in controlling weeds, resulting in yield losses.

Keywords: Arachis hypogaea L., phytotoxicity, yield

\section{Introdução}

Originário da América do Sul, o amendoim (Arachis hypogaea L.) é uma leguminosa utilizada para alimentação humana e animal. É uma ótima opção na rotação de culturas como em cana-de-açúcar, pois aproveita muito bem o adubo residual (Gerin et al., 1996) e tem a capacidade de fixar nitrogênio atmosférico através da associação com bactérias do gênero Rhyzobium, acrescentando ao solo uma quantidade significativa do elemento (Perin et al., 2003).

O Estado de São Paulo é o principal produtor de amendoim, com produção total de 299,1 mil toneladas. Tal condição se deve principalmente ao plantio do amendoim em áreas de reforma de cana-de-açúcar. Com os avanços tecnológicos deste setor, principalmente em melhoramento genético, com a utilização de novas cultivares e a mecanização de todo processo produtivo nos últimos 14 anos, a produtividade passou de 1.835 para $3.140 \mathrm{~kg}$ $\mathrm{ha}^{-1}$, o que representa um aumento de quase $72 \%$, atingindo, na safra de 2014/2015, 337,1 mil toneladas do produto (CONAB, 2015).

Porém, a produtividade do amendoim pode ser reduzida drasticamente caso não haja um controle efetivo das plantas daninhas. Nesse sentido, Nepomuceno et al. (2005) constataram uma redução de $76 \%$ na produtividade da cultura em resposta à interferência causada pela comunidade infestante.
A demanda de manejo químico no controle das plantas daninhas vem aumentando rapidamente devido a questões de praticidade, eficiência e rapidez na execução oferecida pelos herbicidas. Atualmente, existe a preocupação em se utilizar herbicidas que sejam, simultaneamente, eficazes no controle das plantas daninhas, seletivos à cultura e de baixo risco de contaminação ambiental. Nessa perspectiva, Ricchburg et al. (1996) constataram que o imazapic aplicado a $150 \mathrm{~g} \mathrm{ha}^{-1}$ não foi tóxico para a cultura do amendoim, quando aplicado em pós-emergência. Resultados também constatados por Mattos (2004), que verificaram que a melhor época de aplicação do imazapic foi em pós-emergência, sendo que a partir da dose de $120 \mathrm{~g} \mathrm{ha}^{-1}$ já houve excelente controle das plantas daninhas e menor efeito fitotóxico na cultura.

A escassez de herbicidas disponíveis no mercado para a cultura do amendoim pode ser solucionada por opções advindas da extensão de usos de herbicidas. Existem duas maneiras principais de registro de um novo herbicida, a primeira é decorrente da descoberta de novos mecanismos de ação e/ou novas moléculas, e a segunda provém da extensão do uso de herbicidas já utilizados em outras culturas, mas sem registro para a cultura de interesse. Em virtude disso, este trabalho objetivou verificar a eficácia e a seletividade de herbicidas aplicados isoladamente ou em mistura, no controle de plantas daninhas infestantes da cultura do 
amendoim Runner IAC 886, na região de Jaboticabal, SP.

\section{Material e Métodos}

O experimento foi instalado a campo, no município de Jaboticabal, SP, durante a safra agrícola 2005/2006. O solo utilizado foi um Latossolo Vermelho eutroférrico de textura argilosa. A cultivar de amendoim utilizada foi a Runner IAC 886. As sementes foram tratadas com o inseticida tiametoxam na dose de $77 \mathrm{~g} \mathrm{ha}^{-}$

1 (Cruiser 700 WS $110 \mathrm{~g} \mathrm{ha}^{-1}$ de produto comercial), antes da semeadura.

A semeadura do amendoim foi mecanizada em espaçamento de $0,90 \mathrm{~m}$ distribuindo-se 22 sementes por metro. Usou-se como adubação de base $250 \mathrm{~kg} \mathrm{ha}^{-1}$ da formula 0-20-20 de N-P-K. Ao longo do ciclo do amendoinzeiro foram adotadas as devidas providencias para uma boa condução fitossanitária da cultura, totalizando sete aplicações de fungicida e inseticida. Vinte dias após a semeadura foi realizada a contagem do estande da cultura, sendo verificada a densidade de 11 plantas por metro linear.

O delineamento experimental utilizado foi o de blocos casualizados, com quatro repetições, totalizando 12 tratamentos. As unidades experimentais foram compostas por quatro linhas de semeadura espaçadas a $0,90 \mathrm{~m}$, com seis metros de comprimento, totalizando $21,6 \mathrm{~m}^{2}$, sendo que a área útil avaliada foi de 9,0 $\mathrm{m}^{2}$, equivalendo a duas linhas centrais de cinco metros de comprimento.

Os tratamentos empregados (Tabela 1) foram constituídos de aplicações de herbicidas isolados ou em mistura, em duas épocas de aplicação: pré-emergência e pós-emergência, com as testemunhas sem capina (no mato) e capinada (no limpo). Para o herbicida imazapic, quando aplicado em pós-emergência, adicionou-se $0,5 \%$ de adjuvante $\left(\right.$ Assist $\left.^{\circledR}\right)$ na calda de aplicação.

Tabela 1. Tratamentos, doses, épocas e datas de aplicações dos herbicidas sobre o amendoim cultivar Runner IAC 886. Jaboticabal, SP, 2005/2006.

\begin{tabular}{|c|c|c|c|}
\hline Tratamentos & $\begin{array}{c}\text { Dose } \\
\text { (L ou kg ha-1 de i.a.) }\end{array}$ & Época & Data \\
\hline 1-Imazapic ${ }^{1}$ & 0,098 & Pré & $5 / 11 / 05$ \\
\hline 2-Imazapic ${ }^{1,2}$ & $0,098+0,5 \%$ & Pós & $9 / 12 / 05$ \\
\hline 3-Imazapic + pendimetalina $^{3}$ & 0,098 e 1,25 & Pré/Pré & $5 / 11 / 05$ \\
\hline 4-Imazapic + pendimetalina & $0,098+0,5 \%$ e 1,25 & Pós/Pós & $9 / 12 / 05$ \\
\hline 5-Imazapic + trifluralina ${ }^{4}$ & 0,098 e 2,1 & Pré/Pré & $5 / 11 / 05$ \\
\hline 6-Trifluralina e imazapic & 2,1 e $0,098+0,5 \%$ & Pré/Pós & $5 / 11$ e $9 / 12 / 05$ \\
\hline 7-Trifluralina e bentazon ${ }^{5}$ & 2,1 e 0,72 & Pré/Pós & $5 / 11$ e $9 / 12 / 05$ \\
\hline 8 -Trifluralina e $2,4-\mathrm{D}^{6}$ & 2,1 e 0,6 & Pré/Pós & 5/11e $9 / 12 / 05$ \\
\hline 9-Imazapic e (bentazon + paraquat) ${ }^{7}$ & 0,056 e $0,96+0,6$ & Pré/Pós & $5 / 11$ e $9 / 12 / 05$ \\
\hline 10-Imazapic + (bentazon + paraquat $)$ & 0,056 e $0,96+0,6$ & Pós/Pós & $9 / 12 / 05$ \\
\hline 11-Testemunha sem capina & ------ & ------ & ------ \\
\hline 12-Testemunha capinada & ------ & ------ & ------ \\
\hline
\end{tabular}

${ }^{1}$ Plateau ${ }^{\circledR},{ }^{2}$ Assist ${ }^{\circledR} 0,5 \%$ v/v, ${ }^{3}$ Herbadox ${ }^{\circledR} 500$ CE,${ }^{4}$ Premerlin ${ }^{\circledR} 600$ EC, ${ }^{5}$ Basagran ${ }^{\circledR} 600,{ }^{6}$ Aminol ${ }^{\circledR} 806,{ }^{7}$ Pramato ${ }^{\circledR}$.

Os herbicidas foram aplicados com um pulverizador costal à pressão constante $\left(\mathrm{CO}_{2}\right) \mathrm{de}$ $2,4 \mathrm{kgf} \mathrm{cm}^{-2}$, munido de uma barra com quatro pontas XR 11002 espaçadas 0,5 m entre si e calibrado para aspergir um volume de calda de $200 \mathrm{~L} \mathrm{ha}^{-1}$ (Tabela 2). No momento da aplicação dos herbicidas em pós-emergência, as plantas daninhas dicotiledôneas se encontravam com a terceira folha verdadeira desenvolvidas e as gramíneas com o segundo perfilho. Já as plantas de amendoim encontravam-se em início de florescimento. 
Tabela 2. Condições climáticas durante as aplicações dos herbicidas. Jaboticabal, SP, 2005/2006.

\begin{tabular}{|c|c|c|c|c|c|c|c|c|}
\hline \multirow{2}{*}{ Data } & \multicolumn{2}{|c|}{ Horário (h) } & \multicolumn{2}{|c|}{ Temp. $\left({ }^{\circ} \mathrm{C}\right)$} & \multirow{2}{*}{$\begin{array}{c}\text { Umidade } \\
\text { do solo }\end{array}$} & \multirow{2}{*}{$\begin{array}{l}\text { U.R. } \\
\text { ar }(\%)\end{array}$} & \multirow{2}{*}{$\begin{array}{c}\text { Nebulosidade } \\
(\%)\end{array}$} & \multirow{2}{*}{$\begin{array}{l}\text { Vento } \\
\left(\mathrm{km} \mathrm{h}^{-1}\right)\end{array}$} \\
\hline & Início & Final & $\mathrm{Ar}$ & Solo & & & & \\
\hline $5 / 11 / 05$ & $10: 00$ & $11: 30$ & 30,0 & 31,3 & seco & 65 & 15 & 3 a 5 \\
\hline $9 / 12 / 05$ & 13:00 & $14: 30$ & 33,0 & ------ & seco & 50 & 45 & 4 a 6 \\
\hline
\end{tabular}

Para determinação da composição da comunidade infestante, foram lançados dois quadrados amostrais de $0,25 \mathrm{~m}^{2}$ no centro das entrelinhas das parcelas referentes à testemunha sem capina, no qual verificou-se que a comunidade infestante era composta, no total, por 21 espécies. Dentre elas, destacaram-se em termos de frequência de ocorrência e densidade: capim-carrapicho (Cenchrus echinatusCCHEC), carrapicho-de-carneiro (Acanthospermum hispidum-ACNHI), caruru (Amaranthus deflexus-AMADE), losna-branca (Parthenium hysterophorus-PTNHY), apagafogo (Alternanthera tenella-ALRTE) e capimpé-de-galinha (Eleusine indica-ELEIN).

Avaliou-se a eficácia e a fitotoxicidade dos herbicidas aos 7, 14, 21, 28, 45 e 90 dias após a aplicação. Para a fitotoxicidade foi utilizada a escala proposta pela SBCPD (1995), na qual $0 \%$ representa ausência de intoxicação, e $100 \%$, a morte das plantas de amendoim. Para o controle foi utilizada a escala proposta pela ALAM (1974), na qual 0\% representa ausência controle e $100 \%$ indica o controle total das plantas daninhas.

A colheita das vagens do amendoim, representando a produtividade, foi realizada manualmente aos 120 dias após a semeadura. Coletaram-se as vagens das duas linhas centrais dentro de cada parcela, desprezando-se $0,5 \mathrm{~m}$ das extremidades. Depois de colhido, o material foi deixado secar ao ar livre, para posterior análise. A produtividade foi extrapolada para sacas por hectare.

Os dados coletados foram submetidos à análise de variância pelo teste $\mathrm{F}$ e quando significativo procedeu-se a comparação entre as médias dos tratamentos utilizando o teste de Tukey a 5\% de probabilidade. Os dados originais de notas de controle e fitotoxicidade das plantas foram transformados para arc sen $\sqrt{ } \%$.

\section{Resultados e Discussão}

$\mathrm{Na}$ avaliação de controle das plantas daninhas aos 7 e 14 dias após a aplicação (DAA) dos produtos, verificou-se que os melhores controles foram para os tratamentos 1, 3, 5 e 9 (Tabela 3), com 75,5\% de eficácia no controle das plantas daninhas na primeira avaliação, sendo que o tratamento 3 atingiu valores de $90 \%$ de controle aos 14 DAA. Desta data em diante, para os tratamentos 1,7 e 10 , houve tendência de queda na porcentagem de controle. Já para os demais tratamentos $(2,3,4,5,6,8$ e 9$)$ a melhor eficácia de controle foi observada aos 28 DAA (Tabela 3).

Valochi (2004) também verificou que nos tratamentos com imazapic isolado, ou em mistura com outros herbicidas, aplicados em pré e pós-emergência, proporcionaram redução na densidade e na matéria seca das plantas daninhas durante o período avaliado, principalmente com relação à tiririca. Dentre os tratamentos menos eficazes, pode-se destacar o 7, o qual apresentou, na média, $52,5 \%$ de controle das plantas daninhas ao longo das avaliações, e o 10, que proporcionou uma porcentagem de controle de $52,1 \%$ na segunda avaliação, sendo progressivamente reduzida ao final das avaliações, demonstrando um controle ineficiente das plantas daninhas.

Nepomuceno et al. (2006), estudando os períodos críticos de interferência das plantas daninhas na cultura do amendoim rasteiro, verificaram que o PCPI, por dois anos consecutivos, foi de 23 a 102 dias para o primeiro ano, com uma redução na produtividade de $80 \%$, e para o segundo ano, o PCPI foi de 27 a 91 dias, com redução de $78 \%$. 
Sendo assim, os resultados de controle das plantas daninhas aos 90 DAA demonstraram que a eficácia dos produtos e o período residual de controle, para os tratamentos $2,3,4,5$, e 6 foram satisfatórios para evitar a competição direta entre a cultura do amendoim Runner IAC 886 e a comunidade infestante.

Tabela 3. Porcentagem de controle das plantas daninhas, aos 7, 14, 21, 28, 45 e 90 dias após a aplicação (DAA) dos tratamentos.

\begin{tabular}{|c|c|c|c|c|c|c|}
\hline \multirow{2}{*}{ Tratamentos } & \multicolumn{6}{|c|}{ Épocas de avaliação (DAA) } \\
\hline & 7 & 14 & 21 & 28 & 45 & 90 \\
\hline 1-Imazapic ${ }^{1}$ (Pré) & $75,5 \mathrm{~b}$ & 80,1 abc & $71,7 \mathrm{a}$ & $75,1 \mathrm{ab}$ & $61,6 \mathrm{ab}$ & $53,8 \mathrm{c}$ \\
\hline 2-Imazapic (Pós) & $47,0 \mathrm{c}$ & 64,2 def & $70,7 \mathrm{a}$ & $76,1 \mathrm{a}$ & $69,1 \mathrm{a}$ & $68,1 \mathrm{abc}$ \\
\hline 3-Imaza. + pendim. ${ }^{2}$ (Pré) & $75,5 \mathrm{~b}$ & $90,0 \mathrm{a}$ & $84,2 \mathrm{a}$ & $90,0 \mathrm{a}$ & $65,1 \mathrm{ab}$ & $78,4 \mathrm{ab}$ \\
\hline 4-Imaza. + pendim. (Pós) & $48,5 \mathrm{c}$ & 68,3 cde & $76,4 \mathrm{a}$ & $85,6 \mathrm{a}$ & 78,4 a & $67,6 \mathrm{abc}$ \\
\hline 5-Imaza. + trifl. $^{3}$ (Pré) & $75,5 \mathrm{~b}$ & $85,6 \mathrm{ab}$ & 79,9 a & $84,2 \mathrm{a}$ & $62,2 \mathrm{ab}$ & $68,0 \mathrm{abc}$ \\
\hline 6-Trif. e imaza. (Pré/Pós) & $52,3 \mathrm{c}$ & $75,1 \mathrm{abcd}$ & $75,8 \mathrm{a}$ & $88,5 \mathrm{a}$ & $87,1 \mathrm{a}$ & $87,1 \mathrm{a}$ \\
\hline 7-Trifl. e bent. ${ }^{4}$ (Pré/Pós) & $49,9 \mathrm{c}$ & 59,4 ef & $48,4 \mathrm{bc}$ & $48,3 \mathrm{bc}$ & $58,3 \mathrm{ab}$ & $51,0 \mathrm{c}$ \\
\hline 8-Trifl. e 2,4-D 5 (Pré/Pós) & $57,4 \mathrm{c}$ & 65,1 def & $70,2 \mathrm{a}$ & $71,6 \mathrm{ab}$ & $62,0 \mathrm{ab}$ & $60,9 \mathrm{bc}$ \\
\hline 9-Imaza e (bent.+para.) (Pré/Pós) & $75,5 \mathrm{~b}$ & 73,4 bcde & $68,8 \mathrm{ab}$ & 80,6 a & $66,8 \mathrm{ab}$ & $60,9 \mathrm{bc}$ \\
\hline 10-Imaza + (bent.+para.) (Pós/Pós) & $46,3 \mathrm{c}$ & $52,1 \mathrm{f}$ & $28,0 \mathrm{c}$ & $26,1 \mathrm{~cd}$ & $32,7 \mathrm{bc}$ & $27,1 \mathrm{~d}$ \\
\hline 11-Testemunha sem capina & $5,7 \mathrm{~d}$ & $5,7 \mathrm{~g}$ & $5,7 \mathrm{~d}$ & $5,7 \mathrm{~d}$ & $5,7 \mathrm{c}$ & $5,7 \mathrm{~d}$ \\
\hline 12-Testemunha capinada & $90,0 \mathrm{a}$ & $90,0 \mathrm{a}$ & $90,0 \mathrm{a}$ & $90,0 \mathrm{a}$ & $90,0 \mathrm{a}$ & $90,0 \mathrm{a}$ \\
\hline $\mathrm{F}(\mathrm{Blocos})$ & $2,08^{\mathrm{NS}}$ & $1,38^{\mathrm{NS}}$ & $1,10^{\mathrm{NS}}$ & $1,02^{\mathrm{NS}}$ & $0,82^{\mathrm{NS}}$ & $1,83^{\mathrm{NS}}$ \\
\hline F (Tratamentos) & $59,87 * *$ & $57,17 * *$ & $31,96 * *$ & $25,61 * *$ & $10,60 * *$ & $25,44 * *$ \\
\hline DMS $(5 \%)$ & 14,24 & 14,98 & 21,71 & 26,88 & 35,01 & 23,56 \\
\hline $\mathrm{CV}(5 \%)$ & 9,85 & 8,95 & 13,63 & 15,81 & 22,90 & 15,84 \\
\hline
\end{tabular}

Médias seguidas de mesma letra não diferem entre si ao nível de 5\% de probabilidade pelo teste de Tukey. NS = não significativo pelo teste $\mathrm{F}$ ao nível de $5 \%$ de probabilidade. ** significativo a $1 \%$ de probabilidade. * significativo a $5 \%$ de probabilidade. ${ }^{1}$ Plateau ${ }^{\circledR} ;{ }^{2}$ Herbadox ${ }^{\circledR} 500$ CE; ${ }^{3}$ Premerlin ${ }^{\circledR} 600$ CE; ${ }^{4}$ Basagran ${ }^{\circledR} 600 ;{ }^{5}$ Aminol ${ }^{\circledR} 806 ;{ }^{6}$ Pramato ${ }^{\circledR}$. Dados transformados para arc sen $\sqrt{\%}$.

Para os valores médios das notas de intoxicação atribuídas às plantas de amendoim (Tabela 4), pode-se observar que aos 7 DAA, as menores alterações morfofisiológicas causadas pelos herbicidas nas plantas foram registradas nos tratamentos 7, 2 e 1, com valores de 17,8\%; $24,5 \%$ e 25,5 , respectivamente. Esses dados contrastam se comparados aos de Azania et al. (2004), que trabalhando com imazapic em préemergência na presença ou ausência de palha da cana-de-açúcar, nas doses de 150 e $210 \mathrm{~g} \mathrm{ha}^{-1}$ p.c., obtiveram altos níveis de injurias nas plantas das cultivares Tatu vermelho e IAC-5. Essas diferenças nos resultados podem ser decorrentes de que estes autores utilizaram cultivares diferentes, doses maiores e foram realizados em condições edafoclimáticas distintas.
Já os demais tratamentos, aos 7 DAA, apresentaram variações de 29,7\% (tratamento 4) até $37,0 \%$ (tratamento 9).

A maioria dos tratamentos causou um leve aumento nos sintomas de intoxicação aos 14 DAA, exceto os tratamentos 6, 7, 9 e 10, nos quais a intoxicação nas plantas já se atenuavam. Nesta mesma data, pôde-se observar que o tratamento 7 mostrou-se menos tóxico às plantas de amendoim, cujos sintomas foram sendo gradativamente reduzidos, até sua ausência aos 45 DAA.

Aos 21 DAA, houve, de maneira geral, tendência de redução dos sintomas fitotóxicos para todos os tratamentos, com exceção do tratamento 5, que se apresentou invariável, e dos tratamentos 6 e 8, que apresentaram aumento dos sintomas. Aguiar et al. (1997), estudando o controle das plantas daninhas Cenchrus 
echinatus, Cyperus rotundus, Croton sp., Merremia aegyptia, Desmodium sp. e Blainvillea sp., na cultura do amendoim com vários herbicidas, dentre eles trifluralina, pendimetalina e bentazon, mostraram que nenhum deles proporcionou controle satisfatório para as plantas daninhas estudadas, e que também não se mostraram tóxicos para as plantas de amendoim.

Para a avaliação feita aos 45 DAA, as plantas de amendoim já apresentavam redução na intoxicação, sendo que os tratamentos 7 e 10 estavam totalmente recuperados. No entanto, as plantas dos tratamentos 3 e 5 ainda apresentavam intoxicação (com valores de $23,5 \%$ e 25,2\%, respectivamente). Estes resultados corroboram com os obtidos por Leiderman et al. (1974), que verificaram que o herbicida bentazon controlou satisfatoriamente plantas daninhas dicotiledôneas e não causou injúrias à cultura do amendoim.

Aos 90 DAA todas as plantas não mais apresentavam sintomas de fitotoxicidade.

Tabela 4. Valores médios da porcentagem de intoxicação das plantas de amendoim cultivar Runner IAC 886, aos 7, 14, 21, 28, 45 e 90 dias após a aplicação (DAA).

\begin{tabular}{|c|c|c|c|c|c|c|}
\hline \multirow{2}{*}{ Tratamentos } & \multicolumn{6}{|c|}{ Épocas de avaliação (DAA) } \\
\hline & 7 & 14 & 21 & 28 & 45 & 90 \\
\hline 1-Imazapic ${ }^{1}$ (Pré) & $25,5 \mathrm{bc}$ & $30,7 \mathrm{~b}$ & $15,3 \mathrm{de}$ & $18,4 \mathrm{abc}$ & 3,2 bc & 0,0 \\
\hline 2-Imazapic (Pós) & $24,5 \mathrm{bc}$ & $29,0 \mathrm{~b}$ & 19,9 cde & $18,1 \mathrm{abc}$ & $11,0 \mathrm{abc}$ & 0,0 \\
\hline 3-Imaza. + pendim. ${ }^{2}$ (Pré) & $30,7 \mathrm{ab}$ & $34,7 \mathrm{ab}$ & $29,5 \mathrm{abc}$ & $29,0 \mathrm{a}$ & 23,5 a & 0,0 \\
\hline 4-Imaza. + pendim. (Pós) & $29,7 \mathrm{ab}$ & $31,6 \mathrm{~b}$ & $25,2 \mathrm{bcd}$ & $25,2 \mathrm{a}$ & $11,0 \mathrm{abc}$ & 0,0 \\
\hline 5-Imaza. + trifl. $^{3}$ (Pré) & $31,6 \mathrm{ab}$ & $33,9 \mathrm{ab}$ & $33,9 \mathrm{ab}$ & $28,2 \mathrm{a}$ & $25,2 \mathrm{a}$ & 0,0 \\
\hline 6-Trif. e imaza. (Pré/Pós) & $31,4 \mathrm{ab}$ & $29,9 \mathrm{~b}$ & $32,3 \mathrm{ab}$ & $24,6 \mathrm{a}$ & $6,4 \mathrm{bc}$ & 0,0 \\
\hline 7-Trifl. e bent. ${ }^{4}$ (Pré/Pós) & $17,8 \mathrm{c}$ & $15,1 \mathrm{c}$ & $11,0 \mathrm{e}$ & $7,83 \mathrm{c}$ & $0,0 \mathrm{c}$ & 0,0 \\
\hline 8-Trifl. e 2,4-D 5 (Pré/Pós) & $34,6 \mathrm{a}$ & $38,4 \mathrm{a}$ & 39,9 a & $24,4 \mathrm{a}$ & $15,3 \mathrm{abc}$ & 0,0 \\
\hline 9-Imaza e (bent.+para.) (Pré/Pós) & $37,0 \mathrm{a}$ & $34,7 \mathrm{ab}$ & $22,7 \mathrm{bcd}$ & $20,6 \mathrm{ab}$ & $17,2 \mathrm{ab}$ & 0,0 \\
\hline 10-Imaza + (bent+para) (Pós/Pós) & 36,9 a & $32,4 \mathrm{ab}$ & $24,5 \mathrm{bcd}$ & 8,9 bc & $0,0 \mathrm{c}$ & 0,0 \\
\hline 11-Testemunha sem capina & $0,0 \mathrm{~d}$ & $0,0 \mathrm{~d}$ & $0,0 \mathrm{f}$ & $0,0 \mathrm{~d}$ & 0,0 & 0,0 \\
\hline 12-Testemunha capinada & $0,0 \mathrm{~d}$ & $0,0 \quad \mathrm{~d}$ & $0,0 \mathrm{f}$ & $0,0 \mathrm{~d}$ & $0,0 \quad \mathrm{c}$ & 0,0 \\
\hline $\mathrm{F}(\mathrm{Blocos})$ & $3,42 *$ & $2,58^{\mathrm{NS}}$ & $3,01 *$ & $5,85 * *$ & $1,49^{\mathrm{NS}}$ & - \\
\hline F (Tratamentos) & $10,45^{* *}$ & $24,02 * *$ & $13,37 * *$ & $8,64 * *$ & $6,93 * *$ & - \\
\hline DMS (5\%) & 9,00 & 6,18 & 11,66 & 12,25 & 16,77 & - \\
\hline $\mathrm{CV}(5 \%)$ & 12,34 & 8,18 & 18,83 & 24,50 & 60,87 & - \\
\hline
\end{tabular}

Médias seguidas de mesma letra não diferem entre si ao nível de $5 \%$ de probabilidade pelo teste de Tukey. NS = não significativo pelo teste $\mathrm{F}$ ao nível de $5 \%$ de probabilidade. ** significativo a $1 \%$ de probabilidade. $*$ significativo a $5 \%$ de probabilidade. ${ }^{1}$ Plateau ${ }^{\circledR} ;{ }^{2}$ Herbadox $^{\circledR} 500 \mathrm{CE} ;{ }^{3}$ Premerlin ${ }^{\circledR} 600 \mathrm{CE} ;{ }^{4}$ Basagran ${ }^{\circledR} 600 ;{ }^{5}$ Aminol ${ }^{\circledR} 806$; ${ }^{6}$ Pramato ${ }^{\circledR}$. Dados transformados para arc sen $\sqrt{ } \%$.

Com relação à produtividade do amendoim (Figura 1), observou-se que os tratamentos 2, 3, 4, 5, 6, 7, 8 e 12 apresentaram melhores respostas para essa variável, não diferenciando significativamente entre si. No entanto, a testemunha capinada ainda apresentou maior produtividade, sendo $7,9 \%$ maior que o tratamento 3 , e $105 \%$ maior que o tratamento 10. Tais resultados vão ao encontro dos obtidos por Grassi \& Leiderman (1974), que ao trabalharem em solos arenosos, observaram que o trifluralina a $0,75 \mathrm{~kg} \mathrm{ha}^{-1}$ i.a. proporcionou um bom controle das plantas daninhas monocotiledôneas, não sendo observado nenhum prejuízo ao desenvolvimento das plantas e à produtividade do amendoim.

Os tratamentos 1 e 9, que diferiram estatisticamente da testemunha capinada, proporcionaram menores valores de produtividades que os demais, como observado 
no trabalho de Ricchburg et al. (1996), os quais constataram que o imazapic aplicado a $150 \mathrm{~g}^{-}$ ${ }^{1}$ não foi tóxico para a cultura do amendoim em pós-emergência, embora causasse redução de até $15 \%$ na produtividade quando aplicado em pré-emergência. Porém, Grichar (1997) obteve as maiores produtividades na cultura do amendoim (1.970, 2.540 e $2.220 \mathrm{~kg} \mathrm{ha}^{-1}$ ) quando aplicou o imazapic em pós-emergência inicial a 50, 60 e $70 \mathrm{~g} \mathrm{ha}^{-1}$, respectivamente, comparativamente a outros herbicidas. Trabalhando com imazapic e imazethapyr a 70 $\mathrm{g} \mathrm{ha}^{-1}$ em pós-emergência, Grichar \& Nester (1997) obtiveram valores de produtividade maiores para o imazapic (3.570 a $\left.4.050 \mathrm{~kg} \mathrm{ha}^{-1}\right)$.

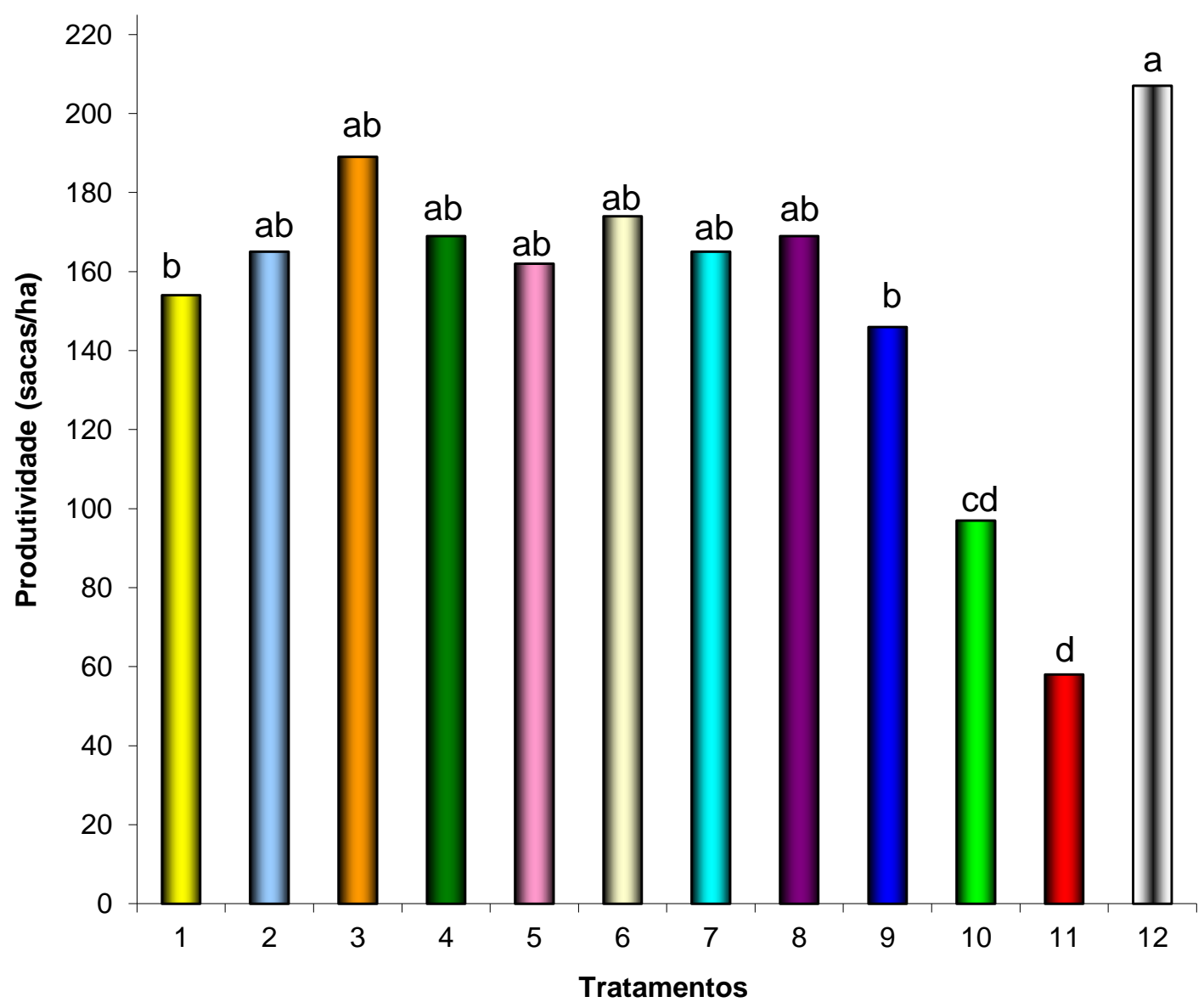

Figura 1. Produtividade média do amendoim em casca Runner IAC 886 (sacas ha ${ }^{-1}$ ), com seus respectivos tratamentos, obtidos através da análise de variância.

Mattos (2004) constatou que a melhor época de aplicação do imazapic foi em pósemergência, sendo que a partir da dose de $120 \mathrm{~g}$ $\mathrm{ha}^{-1}$ já houve excelente controle das plantas daninhas e menor efeito fitotóxico na cultura, corroborando com os resultados deste trabalho.

Os menores valores de produtividade do amendoim foram registrados nos tratamentos 10 e 11, diferindo significativamente dos demais. A redução da produtividade na testemunha sem capina, quando comparada à capinada, foi de $72 \%$, comprovando que o controle das plantas daninhas é de fundamental relevância para se minimizar o prejuízo na queda de produtividade quando em convivência com as plantas daninhas. Esse resultado corrobora com os 
obtidos por Nepomuceno et al. (2005), que em uma área de estudo com predomínio de Cyperus rotundus, Commelina benghalensis e Euphorbia heterophylla, constataram que a produtividade do amendoim foi reduzida em $76 \%$ devido a interferência da comunidade infestante, demonstrando assim a necessidade de controle.

\section{Conclusões}

Pelos resultados encontrados pode-se concluir que na cultura do amendoim cultivar 'Runner IAC 886', para uma comunidade infestante composta por capim-carrapicho, carrapicho-de-carneiro, caruru, losna-branca, apaga-fogo e capim-pé-de-galinha, o melhor controle das plantas daninhas foi obtido por imazapic em pós-emergência; já a aplicação de imazapic + (bentazon + paraquat) em pósemergência, não foi efetivo no controle das plantas infestantes, resultando em perdas de produtividade.

\section{Referências}

AGUIAR, J.C. et al. Controle químico de plantas daninhas na cultura do amendoim (Arachis hypogaea L.) no estado do Ceará. Ciência Agronômica, v.28, n.1-2, p.56-63, 1997.

ALAM - $r$ ASOCIACIÓN
LATINOAMERICANA DE MALEZAS.
Recomendaciones sobre
sistemas de evaluación en ensayos de control
de malezas. ALAM, v.1, n.1, p.35-38, 1974.

AZANIA, C.A.M. et al. Seletividade do Imazapic para dois cultivares de amendoim (Arachis hypogaea L.) cultivados na ausência e na presença de palha de cana-de-açúcar. Planta Daninha, v.22, n.1, p.145-150, 2004.

CONAB - COMPANHIA NACIONAL DE ABASTECIMENTO. Acomp. safra bras. grãos, v.2 - Safra 2015/15, n.9 - Nono Levantamento, p.1-104, 2015. Disponível em: <http://www.conab.gov.br/OlalaCMS/uploads/ arquivos/15_06_11_09_00_38_boletim_graos_ junho_2015.pdf >. Acesso em: 11 de julho de 2015.

GERIN, M.A.N. et al., Adubação do amendoim (Arachis hypogaea L.) em área de reforma de canavial. Scientia Agricola, v.53, n.1, p.84-87, 1996.

GRASSI, N.; LEIDERMAN, L. Estudos comparativos de herbicidas para amendoim. In: SEMINÁRIO BRASILEIRO DE HERBICIDAS E ERVAS DANINHAS, 10., 1974, Santa Maria. Resumos... Santa Maria: Sociedade Brasileira de Herbicidas e Ervas Daninhas, 1974. p.27.

GRICHAR, W.J. Control of palmer amaranth (Amaranthus palmeri) in peanut (Arachis hypogaea L.) with postemergence herbicides. Weed Technology, v.11, n.4, p.739-743, 1997.

GRICHAR, W.J.; NESTER, P.R. Nutsedge (Cyperus spp) control in peanut (Arachis hypogaea L.) with AC 263,222 and imazethapyr. Weed Technology, v.11, n.4, p.714-719, 1997.

LEIDERMAN, L.; GRASSI, N.; SANTOS, C.A.L. Bentazon - novo herbicida de pósemergência para amendoim e soja. In: SEMINÁRIO BRASILEIRO DE HERBICIDAS E ERVAS DANINHAS, 10, 1974, Santa Maria. Resumos... Santa Maria: Sociedade Brasileira de Herbicidas e Ervas Daninhas, 1974, p. 47.

MATTOS, E.D. Eficácia no controle de plantas daninhas e seletividade do herbicida Imazapic ao amendoim (Arachis hypogaea L.). 2004. 81f. Dissertação (Mestrado em Agronomia) - Faculdade de Ciências Agrárias e Veterinárias, Universidade Estadual Paulista.

NEPOMUCENO, M. et al. Interferência das plantas daninhas na cultura do amendoim rasteiro. In: ENCONTRO SOBRE A CULTURA DO AMENDOIM, 2., 2005, Jaboticabal. Anais... Jaboticabal: Faculdade de Ciências Agrárias e Veterinárias, 2005. 
NEPOMUCENO, M. et al. Interferência das plantas daninhas na produção do amendoim, em dois anos consecutivos, na região de Jaboticabal. In: ENCONTRO SOBRE A CULTURA DO AMENDOIM, 3., 2006, Jaboticabal. Anais... Jaboticabal: Faculdade de Ciências Agrárias e Veterinárias, 2006.

PERIN, A.; GUERRA, J.G.M.; TEIXEIRA, M.G. Cobertura do solo e acumulação de nutrientes pelo amendoim forrageiro. Pesquisa Agropecuária Brasileira, v.38, n.7, p.791-796, 2003.

RICCHBURG, J.S. et al. Weed management in southastern peanut (Arachis hypogaea) with AC 263,222. Weed Technology, v.10, n.1, p.145152, 1996.

SBCPD - SOCIEDADE BRASILEIRA DA CIÊNCIA DAS PLANTAS DANINHAS. Procedimentos para instalação, avaliação e análise de experimentos com herbicidas. Londrina: 1995. 42p

VALOCHI, R. Eficácia de controle e seletividade de herbicidas para dois cultivares de amendoim. 2004. 59f. Monografia (Graduação em Agonomia) Faculdade de Ciências Agrárias e Veterinárias, Universidade Estadual Paulista. 